\title{
Teaching Leadership in the Experience Economy Paradigm
}

\author{
Lori L. Moore \\ Associate Professor \\ Texas A\&M University \\ Jacklyn A. Bruce \\ Associate Professor \\ North Carolina State University
}

\section{Introduction}

Anyone involved in higher education today faces challenges. We are being asked to provide the best, most relevant education for today's diverse student population while facing increasing budget cuts, and at the same time assess and demonstrate the student learning taking place. The argument can be made that students are an educator's customers. It can also be argued that leadership educators strive to engage students (customers) through the various teaching strategies they employ within their programs, classrooms, or other contexts. In a world with greater emphasis being put on the bottom line of education, we cannot deny the importance of recruiting happy customers (students) who continue to return to our programs. For leadership educators, this means we must meet the needs of our "customers" without diluting or devaluing the educational process and intended outcomes of higher education.

Students today have been described as consumer oriented, entertainment oriented, and entitled (Taylor, 2006). Taylor (2006) noted,

Any topic, class, or field that cannot demonstrate its utility and meaning to each student will be suspect... The ability of each instructor to articulate a rationale for the necessity of their subject based on real world application is a necessary but not sufficient prerequisite for students to develop such necessary applications and subsequent value. Pedagogical activities must be available so each student can apply information to her/his own past, present, and future life. (p. 2:52)

Graham, Dezuanni, Arthurs, and Hearn (2015) noted that the higher education sector (HE) still sees itself in the information business and mistakenly continues to operate under the assumption that to survive, they must sell a commoditized form of information. "The HE sector risks significant long-term damage if it continues to see itself as an information-services provider or broker" (Graham et al., 2015, p. 112). Because so much information is available for free, almost instantly, from a variety of sources on the internet, the authors argue that the value of information itself is almost zero, and therefore, higher education must move towards an experience economy to survive (Graham et al.). According to Graham et al.,

The long-term relevance of a systematically functional HE sector means moving away from an emphasis on organizing, packaging, and disseminating information toward an emphasis on facilitating meaningful pedagogic experiences based on a knowledge of student capabilities and the affordances of locale. (p. 117) 
Leadership educators face a difficult challenge creating meaningful pedagogical experiences for students that engage all of the senses while reinforcing the various actions and practices necessary for leadership in a way that students today find engaging.

\section{Background \& Review of Related Literature} noted,

Experiential learning is a term many leadership educators are familiar with. Kolb (1984)

In the field of higher education, there is a growing group of educators - faculty, administrators, and interested outsiders - who see experiential education as a way to revitalize the university curriculum and to cope with many of the changes facing higher education today. (p. 4)

However, what constitutes an experience? An experience "is not an amorphous construct; it is as real an offering as any service, good, or commodity" and "occurs when a company intentionally uses services as the stage, and goods as props, to engage individual customers in a way that creates a memorable event" (Pine \& Gilmore, 1998, p. 98). Similarly, Graham et al. (2015) stated, "the experience cannot be based on mass-mediated, commoditized, standardized, globally brokered information packages; it must be based, instead on facilitated experiences" (p. 117). Pine and Gilmore (1998) described experiences as internal: "Experiences are inherently personal, existing only in the mind of an individual who has been engaged on an emotional, physical, intellectual, or even spiritual level" (Pine \& Gilmore, 1998, p. 99). The value of experiences lies in the memories created by individuals who engaged in them (Pine \& Gilmore, 2011): "Although experiences themselves lack tangibility, people greatly desire them because the value of experiences lies within them, where it remains long afterward" (Pine \& Gilmore, 2011, p. 19).

Using the notion of Experience Economy described by Pine and Gilmore (1998), experiences can be sorted into four realms along the spectrum of two dimensions: participation and connection. The first dimension relates to the level of customer or guest participation with passive participation at one end and active participation at the other end (Pine \& Gilmore, 1998, 2011). Passive participation implies "customers do not directly affect or influence the performance" while active participation occurs when "customers personally affect the performance or event that yields the experience" (Pine \& Gilmore, 2011, p. 45). A lecture on leadership would fall more toward the passive end of the spectrum, where a role-playing activity would fall more toward the active participation end. The second spectrum relates how the learner receives the experience, similar to context. "At one end of this spectrum lies absorptionoccupying a person's attention by bringing the experience into the mind from a distance - and at the other end is immersion-becoming physically (or virtually) a part of the experience itself"

(Pine \& Gilmore, 2011, pp. 45-46). In other words, the learner either absorbs the experience, like reading a leadership textbook, or is immersed in the experience, like actively engaging in an experiential learning activity.

Coupling these dimensions defines Pine and Gilmore's $(1998,2011)$ Four Realms of an Experience: (a) entertainment (passive participation; absorption); (b) educational (active participation; absorption); (c) escapist (active participation, immersion), and (d) esthetic (passive participation, immersion). Pine and Gilmore (2011) concede that while many experiences engage 
primarily through one of the four realms, most cross boundaries into one or more of the others as well. "Generally, we find the richest experiences - such as going to Disney World or gambling in a Las Vegas casino - encompass aspects of all four realms, forming a "sweet spot" around the area where the spectra meet" (Pine \& Gilmore, 1998, p. 102).

These researchers go further to tell us what leadership educators have long embracedexperiences are as "real" as any other commodity. However, key to the Pine and Gilmore (1998) paradigm is the notion that "to realize the full benefit of staging experiences, however, businesses must deliberately design engaging experiences that command a fee" (p. 98). They pose five key experience design principles: (a) Theme the experience, (b) Harmonize the experience with positive cues, (c) Eliminate negative cues, (d) Mix in memorabilia, and (e) Engage all five senses.

\section{Exposition of the Idea/Potential Practice}

If it is true that not providing consistently engaging experience will cause our customers to seek experiences elsewhere, then being able to employ the notion of the experience economy is one way educators can stay on the cutting edge. If students are, in fact, consumers of our courses, then our offerings should be framed in a way that gives our consumers what they want. With that in mind, we would share the following ideas to help instructors effectively employ this notion of the experience economy into their classrooms, employing the five design principles of Pine and Gilmore (1998).

Entertainment Experiences (passive participation; absorption) Example activities for the entertainment category include: Case Studies, Guest Speakers, In-class Short Writing, Interactive Lecture/Discussion, Lecture, Media Clips, Story or Storytelling.

Activity: Stories and Story Telling

Topic: Servant Leadership

1. Theming the experience: "A Day at the Wax Museum". Each class member will use nonfictional story telling to share with fellow classmates about a servant leader. Leaders will be chosen by students but approved by the instructor.

2. Harmonize with positive clues: Dress up as a museum tour guide for the day. Provide the students with admission tickets to the museum. If possible, decorate the learning environment.

3. Eliminate negative cues: Remove anything in the classroom (fliers, notices, etc.) that does not support the theme of the day.

4. Mix in memorabilia: Students should dress in costume for the experience - taking on the role of the leader whose story they will tell. Instructors should provide a take away for each servant leader (a prayer on a book mark for example, for Mother Theresa)

5. Engage all five senses: Students should bring in sights and sounds from the time of their servant leader; music, food, perfumes, all are fair game to help classmates get to know their servant leader.

Activity: Media Clips

Topic: Situational Leadership 
1. Theming the experience: "A Day at the Cinema". Provide the class with examples of situational leadership via the use of cinematic media clips.

2. Harmonize with positive clues: Dress up as a movie theater usher. Carry a big flashlight. Provide the students with admission tickets to the movies. If possible, decorate the learning environment.

3. Eliminate negative cues: Take down anything in the classroom that does not support the theme of the day. Walk through thematic content to reduce any "shock" factor from movie content.

4. Mix in memorabilia: If possible, cover the chairs to look more like a theater. Provide postcards of the clips you will watch for review after the experience. Use the movie posters as the backdrop of the postcards.

5. Engage all five senses: Provide popcorn in tubs and "movie theater candy". If possible, have tech support help you provide a surround sound experience using classroom technology available to you.

Educational (active participation; absorption) Example activities for the educational category include: Class Discussion, Group Projects/Presentations, Individual Leadership Development Plans, Small Group Discussions.

Activity: Individual Leadership Development Plans

Topic: Skills Approach to Leadership

1. Theming the experience: "A New Path to a New You". Guide the students in the development of personal leadership development plans.

2. Harmonize with positive clues: Prepare a plan for yourself for the semester. Plan to be the first person to discuss your plan and your development as the semester progresses. Have the class come up with their own progress milestone markers.

3. Eliminate negative cues: Set ground rules that include the banning of the word "can't", eliminate anything that does not promote the theme.

4. Mix in memorabilia: Provide students with a "key" to their path. When they reach certain milestones, provide them with coupons or certificates that they can turn in for middle of the way rewards.

5. Engage all five senses: Decorate the room the day you present the assignment with a yellow brick road or something similar. Have a similar chart that the students can always reference (for example something electronically), that shows their progress and the progress of their classmates. Have periodic reward days where food and music helps the group celebrate progress. At the end of the experience plan a demonstration of the new skills where each student will show off their new skills and talk about what they learned about themselves.

Activity: Group Projects

Topic: Leadership and Culture

1. Theming the experience: "Around the World in a Leadership Day". Divide the class into groups for culturally based leadership presentations. The groups will chose a cultural group that should be approved by the instructor.

2. Harmonize with positive clues: Dress up as a tour guide on the day the assignment is assigned. Carry a globe. If possible, decorate the learning environment. 
3. Eliminate negative cues: Help the group set ground rules that will eliminate negative stereotypes about cultures, particularly addressing language use. Take down anything in the classroom that does not support the theme of the day.

4. Mix in memorabilia: Cover the walls of the rooms with pictures of travel destinations and possible cultural groups. Provide postcards cultural locations that are possibilities with details of the assignment on the back. Provide the students with travel tickets.

5. Engage all five senses: Provide examples of the kinds of food, music, beverages, and textiles that the groups will also be expected to provide. Provide a mentor for each group that will help guide the group through cultural nuances while they research the leadership culture of their assigned group. Have students dress in culturally appropriate garb and provide food, beverages, and textiles that are indicative of their culture.

Escapist (active participation; immersion) Example activities for the educational category include: Games, Icebreakers, Interview of a Leader, Role Play Activities, Service Learning, Simulation, Student Peer Teaching, Teambuilding.

Activity: Ice Breakers

Topic: Building Community

1. Theming the experience: "We Built This City on Leadership". Engage in icebreakers together themed around music. Ice breakers can be individual, small group, whole group, or a combination. Keep the group moving swiftly from one ice breaker to the next-no breaks.

2. Harmonize with positive clues: Dress up as your favorite rock star. Participate in each ice breaker as a "regular" participant while also playing the role of the instructor. This demonstrates your ability to lead while being a part of the community being built. Use popular musicians/singers/bands as your examples.

3. Eliminate negative cues: Take down anything in the classroom that does not support the theme of the day.

4. Mix in memorabilia: Make name-tags shaped like music notes or guitars. Incorporate the music theme into the course ground rules for the day. For example-no one can speak while someone else is speaking - we share the stage.

5. Engage all five senses: Playing music is essential. Use a variety of music to help set the stage and scene for each icebreaker. Provide themed food ("rock and rolos", "guitar picks and dip", etc.)

Activity: Service Learning

Topic: Motivation

1. Theming the experience: "I Can Tell You Why". Create a class level service learning experience. Students should be participant observers, reflecting on their own reasons for serving at the beginning and at the end of the experience, while also observing and evaluating the potential motivations of others on the project.

2. Harmonize with positive clues: Participate as both leader and active participant in the service project. Dress appropriately to give the assignment.

3. Eliminate negative cues: Take down anything in the classroom that does not support the theme of the day. 
4. Mix in memorabilia: Cover the walls of the rooms with pictures of the service destination and (if possible) examples of what the group might be doing. Provide pictures of site contacts with information about each individual and the site so that students can start learning.

5. Engage all five senses: Because very likely any service event will be handled off site of the normal class experience, engaging the five sense will need further planning and coordination with the site. Food, music, and dress parameters will still need to be considered, but likely need to be approved by the site. Depending on your servicelearning site, engage your students in a sensory exploration ahead of time. For example, if the service project will take place with a school for the blind, have the students spend a class session without sight. You as the instructor should also be participating in the adaptation (spend a class period without sight) but also attempt to adopt a class session for students who would need that type of accommodation.

Esthetic (passive participation; immersion) Example activities for the esthetic category include: Exams, Quizzes, Reflective Journals, Research Project/Presentation, Self-Assessments \& Instruments.

Activity: Reflective Journal

Topic: End of course reflection

1. Theming the experience: "It was the Best of Times and the Worst of Times". Assign a class reflection journal that students will use throughout the experience. Students should complete more than a minimum numbers of posts. The content of the posts will be guided by the instructor to include not just the "good", or "positive" or "aha" moments but also times that were "challenging", "difficult", or "bad". This could be done long hand, in a journal, or electronically in a blog or class website. All journals should be accessible to the instructor, but students can choose how they would share their journals with their classmates.

2. Harmonize with positive clues: Journal throughout the semester yourself and be ready to share in order to encourage the students to share. Examples of journal entries should be provided during the course and throughout the experience. Cues and prompts should be given with choices (for example, provide five prompts per entry but require only three).

3. Eliminate negative cues: Help the group set ground rules for what can and should be included in the journals and for how to discuss journal entries in class. This will help pave the way for students to provide an inclusive environment for one another.

4. Mix in memorabilia: Make journals a part of each class experience, so have them for the students at each course, or make it a practice that the students bring the journals to each course. Purchase special pens for the students to use with their journaling (if journaling long hand- potentially advertising your academic program perhaps). If journaling electronically, provide a jump drive for students to have their journals with them each time they attend class.

5. Engage all five senses: When journaling during class time, encourage students to go past surface reflection. Set the stage by playing music that encourages meditation or deeper thinking. Set the lights so that students have enough light to complete the task, but not so that it is disruptive. Provide snacks/drinks to stave off hunger related lack of focus. 
Activity: Self-Assessment

Topic: Beginning of the course opening

1. Theming the experience: "What Do I Know About Me". Provide a set of assessments for the students that will help them conceptualize their leader identities. These assessments should be in the form of a book or journal where students have them all in one place, and have the opportunity to journal or reflect/react after each assessment. Reflections should center on how well the students thought they knew themselves, versus what the assessments might say about them.

2. Harmonize with positive clues: You should also have a journal and assessments with reflections. Be ready to share your assessments and talk about how yours are similar or different than how you see yourself.

3. Eliminate negative cues: Set rules for how to discuss journal entries in class. This will help increase inclusivity and an environment that fosters growth.

4. Mix in memorabilia: The assessment journal itself will be memorabilia and should be created in such a way that students think of it as such. Think Dr. Seuss's Big Book of Me for inspiration.

5. Engage all five senses: As with the journaling, each time that the students are asked to do an assessment and related reflection/response.

\section{Conclusions and Recommendations}

Pine and Gilmore (1998) tell us that if consistently engaging experiences are not provided, our consumers will go elsewhere. To recruit and retain the highest quality students, our course offerings should be consistently refreshed, allowing them to be immersed, active participants in their learning. Embracing the design principles provided by Pine and Gilmore (1998, 2011), while not a guarantee of success, could be used as a guide in trying to answer the increasing demands of an ever more consumer-oriented student base. As they so eloquently noted, "from now on, leading-edge companies - whether they sell to consumers or businesses will find that the next competitive battleground lies in staging experiences" (Pine \& Gilmore, 1998, pp. 97-98). We recommend that instructors select and use these engaging activities strategically to augment their overall program. We are not suggesting they be overused and certainly not used at the detriment to the rigor and relevance of their overall program.

We also recommend that instructors push their own comfort zones. Speaking from experience, dressing up and playing a role may not be in the wheelhouse of every instructor, but encouraging your own growth and development as an instructor also provides a strong message for our students that we are also lifelong learners. Further we recommend significant reflection from the instructors as they go through these experiences to take their own temperatures. This will, again, help in your own development and gauge where you can seek others' expertise or professional development to deepen your toolkit.

Ground rules are an essential piece of each experience. Not only do ground rules keep everyone on the same page in terms of the classroom "rules," but also helps to promote a progressive and inclusive environment where all experiences are validated. Start out with general classroom ground rules, and then add rules for each experience as appropriate. Students should drive the ground rule creation and then keep them in two ways, one copy in the classroom where 
they are visible for each class meeting, and a copy for each student to hold onto as they attend class sessions, study sessions, and group meetings. Remind the group of the rules early and often.

Finally, instructors should tap into their creative side. As instructors, we may adopt the notion that "if it ain't broke, don't fix it." We challenge all instructors, ourselves included, to try out this model of framing experiences for their classes. Evaluate the experiences from both your perspective and the perspective of your students. Discover what is working and what needs to be tweaked as you deliver these experiences for your students. Seek out others who can help you provide these learning experiences. Share and support each other's practice. Finally, have funafter all- it's much more fun to learn when learning is fun!

\section{References}

Graham, P., Dezuanni, M., Arthurs, A., \& Hearn, G. (2015). A Dewyan experience economy for higher education. Cultural Politics, 11(1), 11-125.

Kolb, D. A. (1984). Experiential learning: Experience as the source of learning and development. Upper Saddle River, NJ: Prentice Hall.

Pine, J. P., II, \& Gilmore, J. H. (1998, July-August). Welcome to the experience economy. Harvard Business Review, 76(4), 97-105.

Pine, J. P., II, \& Gilmore, J. H. (2011). The experience economy (updated ed.). Boston, MA: Harvard Business Review Press.

Taylor, M. L. (2006). Generation NeXt comes to college: 2006 updates and emerging issues. In A Collection of Papers on Self-Study and Institutional Improvement, 2, 2:48-2:55. Chicago, IL: The Higher Learning Commission.

\section{Author Biographies}

Lori Moore is an Associate Professor in the Department of Agricultural Leadership, Education, and Communications at Texas A\&M University. She teaches undergraduate and graduate classes in introductory leadership and leadership theory and conducts research on the effectiveness of collegiate leadership programs, including pre-collegiate experiences and leadership education delivery methods. She can be reached at llmoore@tamu.edu.

Jacklyn Bruce is an Associate Professor at North Carolina State University. She can be reached at jackie_bruce@ncsu.edu. 